\title{
The different representations of sparkling wine, convergences and divergences between designation in Brazil and France
}

\author{
M.V. Araujo ${ }^{1,2, a}$, G. Lo Monaco ${ }^{2}$, D. Callegaro de Menezes ${ }^{1}$, and K.L. Bruch ${ }^{1}$ \\ ${ }^{1}$ Center for Studies and Researches in Agribusiness - Universidade Federal do Rio Grande do Sul, Av. Bento Gonçalves, 7712 \\ Porto Alegre, 91540-000, Brazil \\ ${ }^{2}$ Laboratory of Social Psychology - Aix-Marseille Université, Maison de la Recherche, 29 avenue Robert Schuman, 13621 \\ Aix-en-Provence, France
}

\begin{abstract}
This study aims to understand the convergences and divergences between the social representations associated with the different terms used to designate sparkling wine in Brazil and in France. For this purpose, we carried a verbal association task to collect the social representation content in Brazil and France. It was word inductor in Brazil: sparkling wine, sparkling wine moscatel, cider, and Champagne. In France, sparkling wine, pétillant wine, crémant wine, and Champagne. There are common terms used to designate sparkling wine that still confuses consumers. The data was analyzed by ascending hierarchical cluster analysis and presented by a dendrogram. This method evidences the dissimilarity between inductors. The results present on a major cluster with all sparkling wines and another with the Brazilian inductor cider. After, we have also the Brazilian inductor moscatel separated, and show a close similarity between French inductors, Champagne and sparkling wine. Even with it being an exploratory research, the results show start to explain the convergences in the French context, due probably to the long history of these products. On the other side, in Brazil, the divergence, principally with cider and moscatel, that are recent in the Brazilian market, compared to sparkling wine and Champagne.
\end{abstract}

\section{Introduction}

Originating from an error of conservation of wine, the sparkling wine has become an important product of the world wine sector. The Champagne, leader of sparkling wine [1], sometimes considered as a category apart .[2], since its origin, about 1700 , has become a known product in celebrations, festivities, end-of-year parties and luxury [3]. Moreover, sparkling wine consumption has ganged marketplace over the word. Consumption variation was $32 \%$ in value (euros) and $36 \%$ in quantity [4]. In other cases, non-traditional products have also gained market importance. This is the case of sparkling wine "moscatel" in Brazil [5,6] and "Crémants" in France, which are more accessible wine accessible [7].

However, in France consumers use many designations to sparkling wine - mousseux, pétillant, Champagne, Crémant and other local names. Nevertheless, some terms have a pejorative connotation, as a sparkling inferior to Champagne [8]. So effervescent, sparkling (pétillant), Crémant or Champagne are preferred [9].

In Brazil, beyond the term sparkling - espumante Champagne is very often used to designate effervescent beverages. As sparkling wine, but also cider, an effervescent of apple.

This is a common confusion between Brazilian consumers, due to the general term employed, "sparkling". A booklet has made by the Brazilian wine sector representative (IBRAVIN - Brazilian Institute of wine) to

\footnotetext{
a e-mail: araujovmarcos@gmail.com
}

explain these differences between terms and the sparkling products. According to the IBRAVIN, sparkling wine is just products from the first or second fermentation of grape that produce natural bubbles [10]. However, cider, fermented of fruits, mix alcoholic beverages, soft drink is not considered as sparkling wine. As we can see on the federal low n. 7.678 [11].

As in Brazil, effervescent is a general term used to designate sparkling wines in France [12]. Also, the European Union regulates the production and the terms used to designate sparkling wine [13] to avoid abusive practices against consumers. Due to these many concepts of sparkling wines and "sparkling" products, consumers have different perceptions about this product. In some cases, uncertain perceptions, like cider, or what is really sparkling wine.

A beverage to celebrate and to social purposes [14], sparkling wine is present in many countries and could have different representations or purposes. This symbolic side of sparkling wine is a characteristic of wine in general. Is a product of conviviality and part of the French identity, i.e. [15].

As well as wine, sparkling wine could be considered as a cultural object. In this way, that are cultural and social practices around their consumption. These practices can be evidenced by their social representations [16]. Thereby, social representations are beliefs constructed and maintained socially, which are shared by individuals in the same social group [17]. It is a form of practical knowledge, that contribute to constructing a common reality in a specific group [18]. There is influenced by

(C) The Authors, published by EDP Sciences. This is an Open Access article distributed under the terms of the Creative Commons Attribution License 4.0 (http://creativecommons.org/licenses/by/4.0/). 
Table 1. Distribution of participants by age.

\begin{tabular}{ccccc}
\hline Age & $20-29$ & $30-39$ & $40-49$ & $>50$ \\
\hline Brazil & 94 & 66 & 20 & 31 \\
France & 56 & 20 & 19 & 45 \\
\hline
\end{tabular}

the social context to satisfy a social point of view, group identity and sense of social differentiation [19]. Its content emerges from history and culture [20]. In this way, social representations are social knowledge that have a group relation importance, influenced by the culture and history of some group [18].

Taking the cultural and social differences between Brazil and France, sparkling wine can have different representations associated. This could be due to the origin of wine into both countries. Brazil is a new word wine while France is an old word wine. New word wine has a new relationship with wine, in an innovative way, in opposition to old word wine, as France, is more conservative and keep traditions [21].

Considering these differences and that social representations is universal, but the object of representation, such as wine, varies according to the culture [16] the objective of this study is understanding the convergences and divergences between the social representations associated to the different terms used to designate sparkling wine in Brazil and in France.

\section{Method}

\subsection{Participants}

Three hundred fifteen-one individuals participated in this study. 211 Brazilians (148 women, Mage = 29.43, $S D=10.63)$ and 140 French (102 women, Mage = $33.78, S D=13.00$ ) (see Table 1), most respondents drink wine regularity or occasionally and rather occasionally sparkling wine. Participants proved age, country of origin and sociodemographic information. Respondents born in other countries then Brazil and France were disqualified from the study.

\subsection{Procedure}

Participants were invited in Facebook groups in a snowball sampling to an online questionnaire in French and Brazilian Portuguese. From a methodological point of view, the representational study is conducted by means of a verbal association task [22]. Participants were asked to produce four words or expressions that coming in their mind when we randomly presented one of the four words inductors. In Brazil, the word inductors were: "vinho espumante", "espumante moscatel", "Cider", and "Champagne". In France, the word inductors were: "vin mousseux", "vin pétillant", "vin crémant", and "Champagne".

Completing the verbal association task, participants were invited to rank their answers following an instruction of importance-ranking. Then, they provided the meaning of the words associated with a semantic contextualization. This task facilitates lemmatization and categorization [23,24]. Finally, participants completed a sociodemographic and consumption habitus questionnaire.

\subsection{Data analysis}

The words and expressions collected were lemmatized and categorized, using the semantic contextualization of words [24] to perform an ascending hierarchical cluster analysis [22,25-27] to compare the word dictionary for each inductor and have the similarity and dissimilarity between then see: [27]. That aim is to compare the proximity of the inductors, have the proximity and distances between the different dictionaries [22] in Brazil and in France.

The results are visually presented in a dendrogram $[28,29]$. The dendrogram enables to observe the similarity rates [27].

\section{Results}

We compared by hierarchical cluster analysis the dissimilarity between the eight-word dictionaries, four in which country, having the Euclidean distances between which inductor. Respondents were grouped according to the inductor that was assigned to them. The results are visually presented by a dendrogram that presents the similarity by a single linkage between the 8 variables (inductors), being 1 to 4 , Brazilians inductors, and 5 to 8 , French inductors.

The matrix of dissimilarity between the means of the eight inductors is given in Table 2, as well as the means and standard deviations. The visual representation of the differences is given by the dendrogram of Euclidean distances in Fig. 1.

The comparison between dictionaries is taken from the words associated in each one of the inductors. These were assigned one for each participant randomly. The average shows the number of repetitions of the terms for each inductor. The terms evoked by the respondents received 1 and the remainder 0 . The respondents were then separated by the inductor that they received and then we averaged the responses.

To analyse the dissimilarity, we were interested in differences by country. 1-4 is about Brazilians inductors and 5-8 French inductors. In Brazil, the biggest difference is between Champagne and Cider, and the smallest is between Champagne and "espumante", but as well as between "espumante" and "moscatel". France has a small difference between inductors. The smallest is between champagne and "mousseux" (22.9), and the biggest between "crémant" and "pétillant" (36.3). If we compare France and Brazil, we have the smallest difference between "mousseux" and "espumante" (32.5), and the biggest between "vin pétillant" and "cider" (49.3). The biggest dissimilarity is seen in Brazil, with Champagne to Cider (53.5), and to moscatel (48.2).

Figure 1 present visually the differences between Brazilians and French inductors. To start, we have two clusters, one formed by all sparkling wines in Brazil and France and the last one with just Brazilian inductor cider.

\section{Discussions}

This research aims to understand the convergences and divergences between the social representations of different terms to designate sparkling wine in Brazil and in France. We employed hierarchical cluster analysis in social 
Table 2. Similarity matrix (Euclidean distances coefficient matrix) based on the mean relevance of eight inductors of sparkling wine in Brazil and France.

\begin{tabular}{|c|c|c|c|c|c|c|c|c|c|c|}
\hline & M & S.D. & 1 & 2 & 3 & 4 & 5 & 6 & 7 & 8 \\
\hline 1 - Sparkling Wine (BR) & 4.57 & 4.65 & - & & & & & & & \\
\hline 2 - Moscatel Sparkling wine (BR) & 4.11 & 5.57 & 35.2 & - & & & & & & \\
\hline 3 - Cider (BR) & 4.64 & 6.00 & 45.8 & 42.9 & - & & & & & \\
\hline 4 - Champagne (BR) & 5.00 & 6.51 & 31.9 & 48.2 & 53.5 & - & & & & \\
\hline 5 - Sparkling wine (mousseux) (FR) & 2.97 & 3.03 & 29.8 & 39.8 & 41.7 & 43.5 & - & & & \\
\hline 6 - Sparkling wine (pétillant) (FR) & 3.52 & 5.84 & 32.9 & 46.7 & 49.3 & 45.6 & 30.8 & - & & \\
\hline 7 - Crémant Wine (FR) & 3.40 & 5.06 & 41.6 & 45.0 & 45.7 & 41.8 & 30.3 & 36.3 & - & \\
\hline 8 - Champagne (FR) & 2.07 & 3.29 & 30.3 & 38.2 & 43.6 & 36.7 & 22.9 & 31.0 & 29.2 & - \\
\hline
\end{tabular}

BR - Brazilians inductors; FR - French inductors.

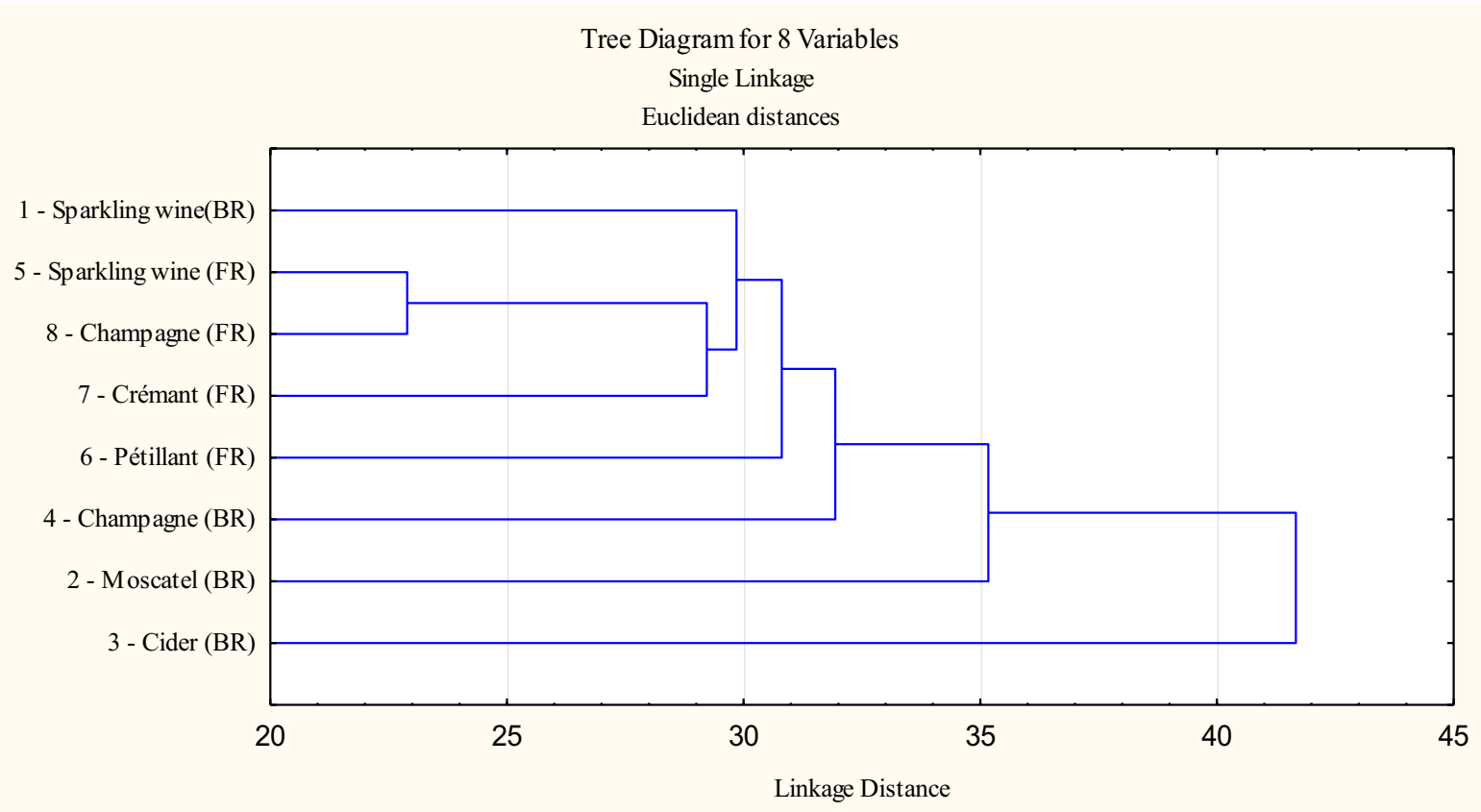

Figure 1. Dendrogram of ascending hierarchical cluster analysis.

representation theory [27] to understand the dissimilarity between the eight inductors, four in Brazil and four in France. This is an exploratory study about the social representations and the social role of sparkling wine in both countries. We used four inductors in Brazil that designate sparkling wine - in Brazilian Portuguese: vinho espumante, espumante moscatel, sidra, and Champagne. And four inductors in France: vin mousseux, vin pétillant, vin crémant et Champagne.

These word inductors are currently used by consumers to designate sparkling wine in both countries. We used them to collect the content of social representations of this object.

From the ascending hierarchical cluster analysis, we can identify first two clusters. The first with the Brazilian inductor cider and the second one with the other sparkling wine. It is important to note that cider is the only inductor that is not considered as a sparkling wine. That is a fermented beverage produced from apple. In the same way, is a sweet and popular product in Brazil. Inside the second cluster, we have the other sparkling wine and subclusters. The closest is sparkling wine (mousseux) and champagne in France, having also a similarity with sparkling wine in
Brazil and Crémant. Sparkling wine moscatel, champagne in Brazil, and pétillant (sparkling wine in France) is also close to this principal cluster.

Such as cider, the moscatel is also a sweet product and sometimes see as a product to beginners. In the case of France, event pétillant being a synonymy of sparkling wine in France, it has differences across then. In another side, Champagne that is often considered a separate category [2], form a cluster with sparkling wine in France. Furthermore, Crément wine is also part of this cluster. This proximity of Champagne and sparkling wine goes in discordance with the theory. Normally, sparkling wine as a pejorative connotation [8].

This similarity can be due to the origin of sparkling wine and the importance of Champagne to this product in France. Champagne is also an important product in Brazil, but that is not the same origin. In another side, Brazilian consumers start to have more knowledge and consume more [5]. However, Champagne remains a prestigious product because of his reputation $[2,30]$. In this sense, results show that in France, a traditional wine producer and consumer have a small dissimilarity between inductors. In Brazil, Champagne to cider and moscatel have the 
biggest dissimilarity, that could be explained by their emergence and social group belonging. Both products have different origin, such as cider, since the XX century, that can be considered recent in the Brazilian market [31]. The sparkling wine moscatel is also new on the Brazilian market [6], that could explain the differences between the inductors.

Nevertheless, it is an exploratory research that shows the first results of a study of social representations. It does not show yet the content of social representations and how is organized. It suggested to analyzing the content more precisely to understand the anchoring and objectification of the social representation $[29,32,33]$ of sparkling wine in Brazil and in France.

This work was conducted during a scholarship to international cooperation (PDSE/CAPES 47/2017) financed by CAPES Brazilian Federal Agency for Support and Evaluation of Graduate Education within the Ministry of Education of Brazil.

\section{References}

[1] G. Liger-Belair, J. Rochard, Les vins effervescents: Du terroir à la bulle (Pratiques, Paris: Dunod, 2008)

[2] A. Morton, C. Rivers, S. Charters, W. Spinks, Qual. Mark. Res. Int. J. 16, 150 (2013)

[3] D. Kladstrup, P. Kladstrup, Champanhe (Rio de Janeiro, Jorge Zahar, 2006)

[4] OIV, "OIV Statistical Report on World Vitiviniculture," Paris, 2018

[5] M.V. Araujo, M.A.C. da Silva, K.L. Bruch, BIO Web Conf. 12, 03012 (2019)

[6] D.A. Wurz, et al., BIO Web Conf. 9, 03008 (2017)

[7] L. Arribard, "Le marché des vins effervescents," Paris, 2015

[8] J. Sterling, Vintage Feasting (New York, Pocket Books, 1996)

[9] F. Collombet, "Mousseux (vins mousseux) Champagne, crémant, effervescent, pétillant," Dico du Vin, 2011, [Online], available: https:// dico-du-vin.com/mousseux-vins-mousseux/ [Accessed: 04-Apr-2019]

[10] K.L. BRUCH, "Nem tudo que borbulha é espumante," Bento Gonçalves, 2012

[11] BRASIL, "Lei n ${ }^{\circ} 7.678$, de 8 de novembro de 1988," 2014. [Online]. Available: http://www . planalto. gov.br/ccivil_03/leis/1980-1988/L7678.htm. [Accessed: 02-Aug-2018]

[12] Syndicat Français des Vins Mousseux, "vin et bulles," Réglementation, 2019. [Online]. Available: http://www .vin-et-bulles.fr/fr/les-vinsmousseaux/reglementation [Accessed: 04-Apr2019]
[13] Official Journal of the European Union, laying down certain detailed rules for implementing Council Regulation (EC) No 479/2008 as regards the categories of grapevine products, oenological practices and the applicable restrictions. European Union: Official Journal of the European Union, 2009, p. L 193/1-59

[14] J. Fountain, C. Lamb, Int. J. Wine Bus. Res. 23, 107 (2011)

[15] C. Simonnet-Toussaint, A. Lecigne, P.H. Keller, J. Int. Des Sci. La Vigne Du Vin. 38, 97 (2004)

[16] M. Mouret, G. Lo Monaco, I. Urdapilleta, W.V. Parr, Food Qual. Prefer. 30, 102 (2013)

[17] G. Lo Monaco, F. Lheureux, S. Halimi-Falkowicz, Swiss J. Psychol. 67, 119 (2008)

[18] D. Jodelet, Les représentations sociales, 5th edn., edited by D. Jodelet (Paris, Presses Universitaires de France, 1989), p. 47

[19] G. Lo Monaco, L. Gaussot, C. Guimelli, Prat. Psychol. 15, 473 (2009)

[20] S. Jovchlovitch, Os contextos do saber: representações, comunicação e cultura (Tradução d. Petrópolis, Vozes, 2008)

[21] G. Banks, J. Overton, J. Wine Res. 21, 57 (2010)

[22] P. Moliner, G. Lo Monaco, Méthodes d'association verbale pour les sciences humaines et sociales (Fontaine, PUG, 2017)

[23] A. Piermattéo, G. Lo Monaco, L. Moreau, F. Girandola, J.L. Tavani, Span. J. Psychol. 17, 1 (2014)

[24] A. Piermattéo, J.-L. Tavani, G. Lo Monaco, Field Meth. 1 (2018)

[25] J.-C. Abric, Méthodes d'étude des représentations sociales, edited by J.-C. Abric, (Toulouse, Éditions Érès, 2003), p. 59

[26] G. Lo Monaco, A. Piermattéo, P. Rateau, J.L. Tavani, J. Theory Soc. Behav. 47, 306 (2016)

[27] A. Clemence, W. Doise, F. Lorenzi-Cioldi, The Quantitative Analysis of Social Representations, Ebook (London, Routledge, 2014)

[28] J.-P. Di Giacomo, Eur. J. Soc. Psychol. 10, 329 (1980)

[29] W. Doise, A. Clemence, F. Lorenzi-Cioldi, Représentations sociales et analyses de données (Grenoble, PUG, 1992)

[30] N. Verdonk, J. Wilkinson, J. Culbert, R. Ristic, K. Pearce, K. Wilkinson, Int. J. Wine Bus. Res. 29, 58 (2017)

[31] A. Nogueira, R.A. Prestes, D.R.S. Simões, J.F. Drilleau, G. Wosiacki, Semin. Ciências Agrárias 24, 289 (2003)

[32] J.-C. Abric, Pratiques sociales et représentations, edited by J.-C. Abric (Paris, PUF, 1994), p. 15

[33] S. Moscovici, Psicologia das minorias ativas (Traduzido, Petrópolis, Vozes, 2011) 